\title{
Immunological effect of co-trimoxazole on platelets
}

\author{
FRANS H J CLAAS, JOS W M VAN DER MEER, JANNEKE LANGERAK
}

\section{Summary and conclusions}

Diminished survival of transfused platelets occurred in two patients given co-trimoxazole, and a third patient taking this drug developed thrombocytopenia. By means of an indirect immunofluorescence assay antibodies against donor platelets coated with co-trimoxazole were found in the sera in all cases. These antibodies were directed against the trimethoprim component of cotrimoxazole and not against sulphamethoxazole.

Co-trimoxazole is a potent antimicrobial agent and is advocated for treatment and prophylaxis in leukaemia. Hence its adverse effect on platelets is of great importance.

\section{Introduction}

Co-trimoxazole (trimethoprim-sulphamethoxazole), a potent antimicrobial drug, is effective in various infections. The antimicrobial activity is due to sequential blockade of the synthesis of folic acid: sulphamethoxazole competes with para-aminobenzoic acid in the synthesis of dihydrofolate, and trimethoprim inhibits dihydrofolate reductase, the enzyme that converts dihydrofolate to tetrahydrofolate. ${ }^{1}$ Reported haematological effects of co-trimoxazole ${ }^{2} 3$ mostly concern megaloblastic transformation, which probably results from the effect of trimethoprim on dihydrofolate reductase. ${ }^{*}$ It is not clear, however, whether thrombocytopenia or neutropenia or both in the absence of megaloblastic changes are also due to trimethoprim or caused by the sulphonamide component. ${ }^{5} 6$

Two patients receiving platelet transfusions showed diminished survival of transfused platelets during treatment with co-trimoxazole, and a third patient taking the drug developed thrombocytopenia and neutropenia. We therefore used an indirect immunofluorescence assay to test sera from these three patients against donor platelets coated with trimethoprim, sulphamethoxazole, and the combined agent.

\section{Subjects and methods}

\section{PATIENTS AND CONTROLS}

Case 1-A 43-year-old man, suffering a blast crisis of chronic myelogenous leukaemia was treated with aggressive chemotherapy (daunorubicin, cytarabine, thioguanine, and cyclophosphamide) and total body irradiation, and given platelet transfusions because of thrombocytopenia. He then began a nine-day course of co-trimoxazole ( 2 tablets twice daily) for a bacterial infection. From day 3 of this treatment poor survival of transfused platelets was observed. When the course ended survival of transfused platelets became normal.

\author{
Department of Immunohaematology, University Medical Centre, \\ Leiden, Netherlands \\ FRANS H J CLAAS, MRC, research fellow \\ JANNEKE LANGERAK, technician
}

Department of Infectious Diseases, University Medical Centre, Leiden, Netherlands

JOS W M VAN DER MEER, MD, consultant in infectious diseases
Case 2-A 20-year-old man received a bone marrow transplant for severe aplastic anaemia, and because of deep thrombocytopenia he was given platelet transfusions. The platelets survived poorly during two periods of six days in which he received co-trimoxazole ( 2 tablets twice daily) for a staphylococcal infection. After stopping the drug survival of the donor platelets became normal.

Case 3-A 52-year-old woman was being treated for staphylococcal spondylodiscitis. Because of penicillin allergy (fever and neutropenia) co-trimoxazole 3 tablets twice daily was instituted. On about the 10th day of treatment neutropenia $\left(20 \times 10^{6}\right.$ granulocytes $\left./ \mathrm{l}\left(20 / \mathrm{mm}^{3}\right)\right)$ and thrombocytopenia $\left(100 \times 10^{9}\right.$ platelets $\left.1\left(100000 / \mathrm{mm}^{3}\right)\right)$ were found. After withdrawing co-trimoxazole there was a slow recovery.

Controls-Five hospital inpatients with normal platelet counts taking co-trimoxazole for various infections and 10 healthy blood donors served as controls.

\section{METHODS}

Platelet survival-Usually preparations from four different donors containing an average of $150 \times 10^{9}$ platelets were transfused. In the absence of immunological destruction this would be expected to increase the circulating platelet count by $20-30 \times 10^{9} / 1(20000-30000 /$ $\mathrm{mm}^{3}$ ) one hour after transfusion (in an adult of about $70 \mathrm{~kg}$ ). Survival of transfused platelets was regarded as poor when the increase was less than $10 \times 10^{9} / 1$.

Isolation of platelets-EDTA blood ( 1 part $5 \%$ sodium EDTA and 9 parts blood) was centrifuged for five minutes at $150 \mathrm{~g}$. The upper layer of plasma containing the platelets was washed three times with phosphate-buffered saline containing $0 \cdot 3^{\circ}{ }_{0}$, sodium EDTA, and a $1 \times 10^{9} / \mathrm{ml}$ suspension was made in this same medium.

Indirect immunofluorescence-Sera from the patients and controls were tested against platelets from healthy donors. Two drops of platelet suspension were incubated with two drops of test serum for 60 minutes at room temperature. After washing three times the platelets were incubated with two drops of TRITC-labelled goatantihuman $\operatorname{IgG}(\mathrm{Fc})$ (Nordic Pharmaceuticals, Tilburg) for 30 minutes at room temperature. The platelets were then washed three times and the preparations examined by immunofluorescence microscopy.

Direct immunofluorescence-Platelets from case 2 were tested by direct immunofluorescence. Two drops of platelet suspension were incubated with two drops of TRITC-labelled goat-antihuman $\mathrm{IgG}(\mathrm{Fc})$ for 30 minutes at room temperature.

Incubation of platelets with antimicrobial agent-Platelets were incubated for 15 minutes at room temperature with $0.1 \mathrm{ml}$ cotrimoxazole $(16 \mathrm{mg}$ trimethoprim and $80 \mathrm{mg}$ sulphamethoxazole $/ \mathrm{ml}$, Wellcome-Nederland BV, Amsterdam), $0.1 \mathrm{ml}$ trimethoprim $(20 \mathrm{mg}$ $\mathrm{ml}$, Wellcome-Nederland BV, Amsterdam), and $0.1 \mathrm{ml}$ sulphamethoxazole $(80 \mathrm{mg} / \mathrm{ml}$, Hoffmann La Roche, Mijdrecht). After washing, the platelets were incubated with the test sera as described for the untreated platelets. The reactions of platelets incubated with each agent were compared with untreated platelets from the same donor.

\section{Results}

In the indirect immunofluorescence tests sera from all three patients were found to contain antibodies against platelets incubated with co-trimoxazole. These antibodies were directed against the trimethoprim component only (table).

During co-trimoxazole treatment in case 2 the patient's platelets were tested by direct and indirect immunofluorescence with his own serum; both tests were positive regardless of whether the platelets had been incubated with co-trimoxazole. Four weeks after stopping co-trimoxazole direct immunofluorescence on the platelets was negative with and without co-trimoxazole incubation. Nevertheless, when the platelets were incubated with co-trimoxazole the indirect immunofluorescence test became positive, indicating that the antibody was still present in his serum. 
Indirect immunofluorescence on donor platelets

\begin{tabular}{|c|c|c|c|c|}
\hline \multirow{2}{*}{ Serum donor } & \multicolumn{4}{|c|}{ Donor platelets incubated with: } \\
\hline & Co-trimoxazole & Sulphamethoxazole & Trimethoprim & Saline \\
\hline Case 1 & + & - & + & - \\
\hline Case 2 & + & - & + & - \\
\hline Case $3 \quad \ldots$ & + & - & + & - \\
\hline Control patients* & - & - & - & - \\
\hline Healthy donors. & - & - & - & - \\
\hline
\end{tabular}

*Treated with co-trimoxazole without thrombocytopenia.

\section{Discussion}

Two of our patients showed decreased survival of transfused platelets during co-trimoxazole treatment. Since co-trimoxazole is advocated for treatment ${ }^{7}$ and prophylaxis in leukaemia ${ }^{8}{ }^{9}$ awareness of this side effect is of great importance. Antibodies against platelets incubated with co-trimoxazole were detected in sera from these patients and in the serum of a patient who developed thrombocytopenia while taking co-trimoxazole. We think that the thrombocytopenia in case 3 and the poor survival of donor platelets in the other patients were probably caused by these antibodies, ${ }^{10}$ since after stopping the drug the survival of donor platelets became normal and the thrombocytopenia disappeared.

In vitro experiments showed that the antibodies reacted against the trimethoprim component of co-trimoxazole, suggesting that in our patients trimethoprim was responsible for the effect on platelets and not the sulphonamide component. The positive direct immunofluorescence test in case 2 during treatment with co-trimoxazole suggests that the binding of trimethoprim and antibody to the platelets also occurs in vivo. After treatment was stopped and trimethoprim was no longer present in the circulation, the test became negative. The indirect immunofluorescence test, however, remained positive after incubation of the platelets with co-trimoxazole, showing that the antibody was still present and that the patient would still be at risk if the drug was readministered. These observations suggest that platelets coated with trimethoprim serve as a neoantigen leading to antibody production.
Drug-induced immune thrombocytopenia has been shown for several other drugs. The best known examples are quinine and quinidine, ${ }^{11} 12$ but allylisoprolacetylcarbamide ${ }^{13}$; sulphafurazole, diazepam, and phenytoin ${ }^{14}$; and rifampicin ${ }^{15}$ have also been implicated. Why some patients develop these antibodies and others do not remains a subject for further study.

We thank Dr H L Haak and Dr J Nauta for their co-operation, Dr J S Thompson and Professor Dr $\mathrm{R}$ van Furth for critically reading the manuscript, and Ms Jeanne van Nassau for preparing the manuscript.

This study was in part supported by the National Institutes of Health (contract NO1-A1-82553); the Dutch Organisation for Health Research (TNO); the Dutch Foundation for Medical Research (FUNGO), which is subsidised by the Dutch Organisation for the Advancement of Pure Research (ZWO); and the J A Cohen Institute for Radiopathology and Radiation Protection.

\section{References}

${ }^{1}$ Bushby, S R M, and Hitchings, G H, British fournal of Pharmacology, 1968, 33, 72 .

2 Salter, A J, Medical Fournal of Australia, 1973, Suppl No 70.

${ }^{3}$ Frisch, J M, Fournal of Infectious Diseases, 1973, 128, Suppl No 175.

+ Ferone, R, Burchall, J J, and Hitchings, G H, Molecular Pharmacology, $1968,5,49$.

${ }^{5}$ Australian Drug Evaluation Committee, Medical fournal of Australia, $1972,1,435$.

${ }^{6}$ Brumfitt, W, Hamilton-Miller, J M T, and Kosmidis, J, fournal of Infectious Diseases, 1973, 128S, 346.

' Grose, W E, Bodey, G P, and Rodrigues, V, Fournal of the American Medical Association, 1977, 237, 352.

${ }^{8}$ Hughes, W T, New England Fournal of Medicine, 1977, 297, 138.

${ }^{9}$ Enno, A, et al, Lancet, 1978, 2, 395

${ }^{10}$ Brand, A, et al, Excerpta Medica International Congress Series, 1977, 415, 639.

11 Shulman, N R, fournal of Experimental Medicine, 1958, 107, 711.

12 Karpatkin, S, American fournal of the Medical Sciences, 1971, 262, 69.

${ }^{13}$ Ackroyd, J F, Clinical Science, 1949, 7, 249.

${ }^{14}$ Cimo, P L, et al, American fournal of Hematology, 1977, 2, 65.

15 Blajchman, M A, et al, British Medical fournal, 1970, 3, 24.

(Accepted 7 August 1979)
ONE HUNDRED YEARS AGO During the last two months, there have been many cases of scarlet fever among the boys at Eton. As is well known, the boys are distributed in the town in the various houses of the tutors and dames. When a case of scarlet fever or other infectious fever appears in a house, the rule is for the tutor to send a circular to the parents of the boys in that particular house informing them of the fact that there is fever in it, and giving them the option of at once removing the boys or of allowing them to remain. If a second case occur in the same house, a second circular is at once addressed to the parents advising them of it. This, as far as it goes, is satisfactory; not so the rule, as we understand it, of the head master, which does not permit a parent to remove his boy from a house in which there is no fever. It must be borne in mind that the boys from an infected house must needs meet-in the playground, the class-room, or the chapelboys from the other houses, and thus make the convection of contagion not only easy but probable. We have high authority for the statement that, in some families, scarlet fever is certain death to the individual it may attack. But, even in its ordinary form, there is always the possibility of some sequela, such as deafness, idiocy, or kidney-disease resulting, and injuring the sufferer for life. Against such a disease, then, no precautions can be deemed too stringent; and we are of opinion that the head master assumes a grave responsibility in refusing a parent the right of removing his child from an appreciable source of danger. During the late epidemic, eight cases of scarlet fever were removed from different houses at Eton and placed in the sanatorium. These have recovered; but one boy, who undoubtedly had scarlet fever, remained in the tutor's house and died from a sequela. This case was in the first instance of a mild nature, and, being regarded as doubtful, was not removed to the sanatorium. For some days after he first suffered from sore-throat and a red flush, he mixed with the other boys. Obviously he should have been sent into the sanatorium, and that none the less because his case was doubtful. It is those very cases in which all the symptoms are not clearly marked which are so dangerous, for the reason that they are allowed to mix with the other boys. No doubt there were other slight cases in the school which were merely regarded as sore-throat, and therefore left at large. The isolation of doubtful cases is doubly useful; it prevents the further spread of disease, and ensures the patient, who in many cases may only be suffering from a slight attack, against those sequelæ to which, for at least three weeks after the inception of the poison, he is as liable as he would be in a more grave attack. The sanatorium is a detached villa standing in some fields a little way out of the town; it contains eight wards, four on each floor. Each ward contains one bed, a window, and a fireplace. The bath was out of order when we visited the sanatorium, and consequently was not being used, although there were seven boys at the time in the sanatorium convalescing from scarlet fever. The linen at the sanatorium is disinfected by being soaked in a solution of chloride of lime, before being sent into the town of Windsor to be washed. It would be better to burn it, or, at all events, have it well baked. Little is at present known as to the mode of action of disinfectants, and it is by no means certain that a solution of chloride of lime, which will not destroy the linen, will destroy the contagion of scarlet fever. At a school like Eton, where as many as nine hundred boys meet every day, there should be provision for continuous medical inspection, so that any suspicious case might be at once isolated. This is the only means of checking the spread of infection. Such an inspection takes place at many large public schools-among them, we believe, Marlborough, Westminster, and Rugby. (British Medical fournal, 1879.) 